\title{
Consanguinity and fetal growth in Pakistani Moslems
}

\author{
M M HONEYMAN, L BAHL, T MARSHALL, AND B A WHARTON \\ Sorrento Maternity Hospital, Birmingham, and Department of Social Medicine, University of Birmingham
}

SUMmary There is conflicting evidence about the effect of parental consanguinity on fetal growth. Previous studies have not always allowed for other factors that are known to affect birth weight, in particular, gestational age, parity, and maternal height. We have therefore studied this question in the Pakistani Moslem population in Birmingham. Babies born to parents who were first cousins were on average $80 \mathrm{~g}$ lighter than those born to unrelated parents, but this difference was not significant for the size of the sample studied. Nor were there any differences in the other measurements of the babies. After expressing birth weight in terms of centiles for gestational age, sex, parity, and maternal height, however, while there was no difference in the overall distribution of centiles, there were more poorly grown babies - that is, weight below the 10th centile-in the first cousin group. We conclude that parental consanguinity is associated with an increase in the number of poorly grown babies but that the overall effect on mean birth weight is small.

While some studies have shown that parental consanguinity retards intrauterine growth, ${ }^{12}$ others have not found this effect. ${ }^{34}$ Even in the studies that found a reduction in birth weight, it was not apparent whether the difference in birth weight was explained by differences in gestational age, parity, maternal height, etc, and not all of the studies controlled for all of these factors when comparing birth weight from different types of marriages.

In this hospital there have been increasing numbers of births to Pakistani mothers who are Moslems, followers of the Islam faith in which consanguinous marriages, particularly among first cousins, are preferred. In previous studies from this hospital it was suggested that environmental factors, such as the mother's health and nutrition in pregnancy, were more important in affecting intrauterine growth than genetic factors..$^{5-7}$

In view of the conflicting evidence described above about the possible growth retarding effect of parental consanguinity, however, this study was designed to consider the effect of consanguinity on fetal growth after allowing for the major factors that affect intrauterine growth-for example, sex of baby, gestational age, maternal height, and parity.

\section{Patients and methods}

Babies born to Pakistani mothers between November 1982 and May 1983 at our hospital were studied.
The mothers were interviewed after the birth by an Asian interpreter who obtained details of the parental relationship, their place of birth, and obstetric history. Further maternal details were ascertained (by MH or LB) from the obstetric notes. The babies were examined within 48 hours of birth (by either $\mathrm{MH}$ or $\mathrm{LB}$ ): any abnormalities were noted, gestational assessment made (Dubowitz method), and length measured by neonatometer, head circumference with a paper tape measure, and skinfold thickness with Harpenden calipers at the left triceps. The birth weight from the labour ward was recorded as measured by the attendant midwife on a spring balance and all details entered onto a proforma.

The size of sample was designed to identify a difference of $100 \mathrm{~g}$ between first cousin and nonrelated babies as significant. ${ }^{8} \mathrm{~A}$ total of 267 mothers were interviewed and 260 completed proformas analysed. Exclusions were due to five stillbirths, one twin pregnancy, and one incomplete form. All babies with congenital abnormalities were included.

Three groups were defined on the basis of the parental relationship-namely, first cousin or closer, more distantly related than first cousin, and unrelated.

Statistical methods. Birthweight centiles, corrected for maternal height, parity, gestational age, and sex of baby using the adjustments of Thomson et al, 
were calculated for each baby, ${ }^{9}{ }^{10}$ as were birthweight and length and head circumference centiles, corrected only for gestational age and sex using the charts of Gairdner and Pearson. ${ }^{11}$

Various measurements of growth and the major variables known to affect birth weight (maternal height, gestational age, sex, and parity) were compared using conventional statistical tests (for metrical variables, such as birth weight, the normal distribution test and for nominal or ordinal variables, such as sex or parity, either $\chi^{2}$ test, Fisher's exact test, or Kolmogorov-Smirnoff test, as indicated in the 'Results' section).

The joint effect of the above four variables and the additional effect of consanguinity in contributing

Table 1 Weight, length, and head circumference at birth of 260 babies grouped according to parental relationships

\begin{tabular}{|c|c|c|c|}
\hline & \multicolumn{3}{|l|}{ Group } \\
\hline & $\begin{array}{l}\text { First cousin } \\
(n=122)\end{array}$ & $\begin{array}{l}\text { Distant } \\
(n=62)\end{array}$ & $\begin{array}{l}\text { Unrelated } \\
(n=76)\end{array}$ \\
\hline $\begin{array}{l}\text { Birth weight }(\mathrm{g}) \text { : } \\
\text { Mean (SD) } \\
\text { No }(\%) \text { below 10th } \\
\text { centile: } \\
\text { Gairdner and }\end{array}$ & $3178(511)$ & $3192(533)$ & $3258(501)$ \\
\hline $\begin{array}{l}\text { Pearsont } \\
\text { Thomson et al } \ddagger\end{array}$ & $\begin{array}{l}31(25 \%)^{*} \\
21(17 \%)^{* *}\end{array}$ & $\begin{array}{l}9(15 \%) \\
4(6 \%)\end{array}$ & $\begin{aligned} 10(13 \%)^{*} \\
4(5 \%)^{* *}\end{aligned}$ \\
\hline $\begin{array}{l}\text { Length (cm): } \\
\text { Mean (SD) } \\
\text { No }(\%) \text { below 10th }\end{array}$ & $50.4(2.40)$ & $50.9(2.78)$ & $50 \cdot 5(1.71)$ \\
\hline $\begin{array}{l}\text { centile } \dagger \\
\text { Head circumference }(\mathrm{cm}) \text { : }\end{array}$ & $17(14 \%) \S$ & $3(5 \%)$ & $5(7 \%) \S$ \\
\hline $\begin{array}{l}\text { Mean (SD) } \\
\text { No (\%) below 10th }\end{array}$ & $34 \cdot 4(1 \cdot 56)$ & $34.3(1.82)$ & $34 \cdot 5(1 \cdot 18)$ \\
\hline centile ${ }^{\dagger}$ & $21(17 \%) \S$ & $8(13 \%)$ & $9(12 \%) \S$ \\
\hline $\begin{array}{l}\text { Mean (SD) triceps } \\
\text { skinfold (mm) }\end{array}$ & $5.76(1.74)$ & $5.73(1.48)$ & $5.94(1.44)$ \\
\hline
\end{tabular}

${ }^{*} \chi^{2}=4.28, \mathrm{p}<0 \cdot 05 .{ }^{* *} \chi^{2}$ with Yates's correction $=5.03, \mathrm{p}<0.05$.

+Gairdner and Pearson for gestational age and sex.

$\ddagger$ Thompson et al for gestational age, sex, parity, and maternal height. ${ }^{9} 10$ §ot significant. to variation in birth weight was explored using multiple regression methods. ${ }^{12}$

\section{Results}

Fetal growth. (Table 1 and Figure). Babies in the first cousin group were $80 \mathrm{~g}$ lighter than those in the unrelated group. This difference was far from significant $(p>0.3)$, but there were significantly more babies below the 10th centile for birth weight in the first cousin group compared with the unrelated group $(p<0.5)$. The babies whose weight was less than the 10th centile were then examined in more detail. Among the 31 light babies in the first cousin group, 16 were also short (length $<10$ th centile), whereas among the 10 light babies in the unrelated group, only one was short ( $\chi^{2}$ with Yates's correction=3.82, $\mathrm{p}=0.05$ ). Among the 31 light babies in the first cousin group, eight had both length and head circumference below the 10th centiles, whereas among the 10 light babies in the unrelated group, only one was symmetrically small (not significant).

Major factors affecting birth weight. (Tables 2 and 3 ). Details of four major factors known to affect intrauterine growth (sex, gestational age, parity, and maternal height) are shown. The first cousin group did not differ significantly in any measurement from the unrelated group.

Multiple regression analysis was performed, and the results are shown in Table 3 . Variation in the four main factors accounted for less than one quarter $\left(r^{2}=22 \cdot 3 \%\right)$ of the variation in birth weight. The additional effect of consanguinity was minimal $\left(r^{2}\right.$ increased by $\left.0.6 \%\right)$.

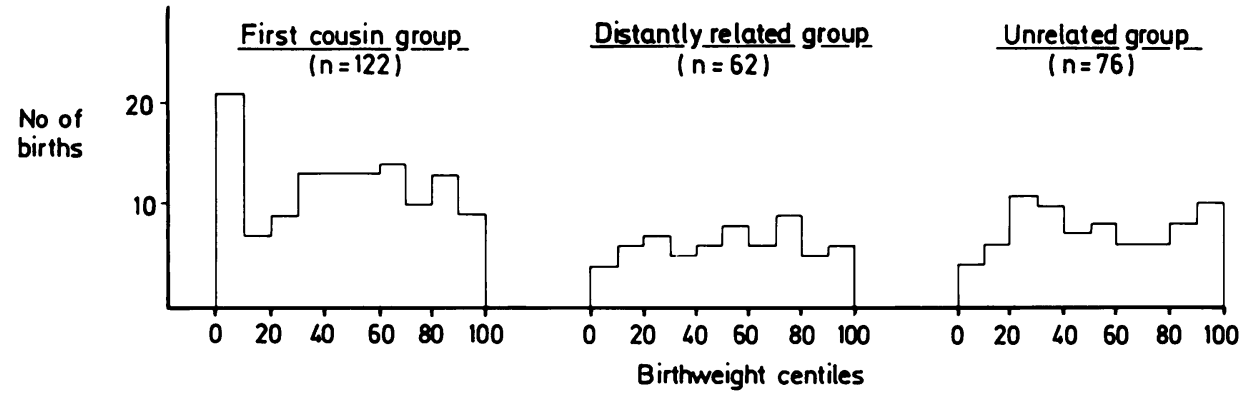

Figure Birth weight centiles for gestation, sex, parity, and maternal height (according to reference data of Thomson et $^{\mathrm{al}^{9}}{ }^{10}$ ) of babies born to first cousin, more distantly related, and unrelated parents. The overall distributions of centiles were not significantly different (Kolmogorov-Smirnoff, $p>0 \cdot 1$ ). The first cousin group contained significantly more babies below the 10th centile, however, $(21(17 \%))$ than the unrelated group $(4(5 \%))\left(\chi^{2}\right.$ with Yates's correction $\left.=5 \cdot 03, p=0=0.025\right)$ but not quite significantly more than in the distantly related group $(4(6 \%))(p-20.08)$. 
Table 2 Major factors affecting birth weight in 260 babies grouped according to parental relationships

\begin{tabular}{|c|c|c|c|}
\hline & \multicolumn{3}{|l|}{ Group } \\
\hline & $\begin{array}{l}\text { First cousin } \\
(n=122)\end{array}$ & $\begin{array}{l}\text { Distant } \\
(n=62)\end{array}$ & $\begin{array}{l}\text { Unrelated } \\
(n=76)\end{array}$ \\
\hline Sex $(M: F)$ & $59: 63$ & $31: 31$ & $38: 38$ \\
\hline \multicolumn{4}{|l|}{ Gestational age (wks): } \\
\hline Mean (SD) & $39 \cdot 3(1 \cdot 0)$ & $38 \cdot 8(2 \cdot 1)$ & $39 \cdot 1(1 \cdot 2)$ \\
\hline No $(\%)<37$ weeks & $2(2)^{*}$ & $6(10)$ & $4(5)$ \\
\hline \multicolumn{4}{|l|}{ Previous births: } \\
\hline Mean (SD) & $1.9(1.7)^{*}$ & $2 \cdot 6(2 \cdot())$ & $2 \cdot 4(2 \cdot 0)$ \\
\hline Nil (No $(\%))$ & $32(26)$ & $10(16)$ & $16(21)$ \\
\hline $1-4($ No $(\%))$ & $70(57)$ & $38(61)$ & $42(55)$ \\
\hline$>4($ No $(\%))$ & $20(16)$ & $14(23)$ & $18(24)$ \\
\hline \multicolumn{4}{|l|}{ Maternal height $(\mathrm{cm})$ : } \\
\hline Mean (SD) & $153 \cdot 2(5 \cdot 6)$ & $154.4(6.4)$ & $154 \cdot 0(6 \cdot 7)$ \\
\hline No $(\%)<150 \mathrm{~cm}$ & $31(25)$ & $12(19)$ & $22(29)$ \\
\hline
\end{tabular}

*Result significantly different from that in distantly related group.

Other factors affecting birth weight. There were no significant differences in maternal age, hypertension, vaginal bleeding, or anaemia between the three groups and no other maternal illness of note. Although none of the mothers smoked cigarettes, two smoked tobacco in a hookah and five took snuff. We did not enquire about alcohol in dealing with a Moslem population. A small number of women $(3 \%)$ had no antenatal care, and of the remainder, roughly half attended before 20 weeks and half after 20 weeks, with a similar pattern in all three groups.

Consanguinity and sociological data. In the overall sample the degree of consanguinity was second cousin or closer in $62 \%$ of marriages, with $47 \%$ of marriages between first cousins, some of whom were probably even more closely related because of a first cousin marriage in the previous generation (this information was not routinely requested). There were no uncle/niece or aunt/nephew parental relationships. Relationships more distant than second cousin occurr d in $9 \%$ of marriages, and in $29 \%$ the parents were unrelated.

Among the 520 parents, $95 \%$ were born in Pakistan: 4\% were born in other regions of the Asian or African subcontinents, with only $1 \%$ born in the United Kingdom. Unskilled factory work was the most usual occupation of the father, but only $56 \%$ of the first cousin group, $70 \%$ of the more distant than first cousin group, and $53 \%$ of the unrelated group were employed.

Congenital malformations. Table 4 shows details of congenital abnormalities of varying severity, all of which occurred within the related groups.

Table 4 Congenital abnormalities in 260 babies grouped according to parental relationships

\begin{tabular}{|c|c|c|}
\hline $\begin{array}{l}\text { Case } \\
\text { No }\end{array}$ & Abnormality & $\begin{array}{l}\text { Birth weight } \\
\text { (g) }\end{array}$ \\
\hline \multicolumn{3}{|c|}{ First cousin $(n=122)$} \\
\hline 1 & $\begin{array}{l}\text { Microcephaly, cataracts, small genitalia, } \\
\text { contractures (Pena Shokeir II) }\end{array}$ & $16(0)$ \\
\hline 2 & Hypoplastic left heart & $400(0)$ \\
\hline 3 & $\begin{array}{l}\text { Dextrocardia, pulmonary stenosis, transposition } \\
\text { great arteries, ventricular septal defect }\end{array}$ & $26(0)$ \\
\hline 4 & Dextrocardia, situs inversus & 3180 \\
\hline 5 & Large ventricular septal defect & 3920 \\
\hline 6 & Intestinal obstruction due to ectopic liver & $34(0)$ \\
\hline 7 & Right congenital dislocation of hip & 2980 \\
\hline 8 & Polydactyly hands and feet & $33(00$ \\
\hline \multicolumn{3}{|c|}{ Distamt $(n=62)$} \\
\hline 9 & Bilateral cleft lip and palate & 3240 \\
\hline 10 & Ventricular septal defect and abnormal thumbs & 2000 \\
\hline
\end{tabular}

Table 3 Regression equations (SE) of birth weight on 'independent' variables and for related parental groups

\begin{tabular}{|c|c|c|c|c|c|c|c|c|}
\hline & \multicolumn{5}{|l|}{ Variable } & \multicolumn{2}{|c|}{ Related group } & \multirow[t]{2}{*}{$r^{2}(\%)^{*}$} \\
\hline & Constant & $\begin{array}{l}\text { Maternal } \\
\text { height }\end{array}$ & Gestation & Sex & Parity & $\begin{array}{l}\text { First } \\
\text { cousin }\end{array}$ & Distant & \\
\hline Birth weight $=$ & $\begin{array}{c}-4566 \\
(1063)\end{array}$ & $\begin{array}{r}+12 \cdot 15 \\
(4 \cdot 69)\end{array}$ & $\begin{array}{r}+150 \cdot 2 \\
(20 \cdot 6)\end{array}$ & $\begin{array}{r}+124 \cdot 2 \\
(57 \cdot 1)\end{array}$ & $\begin{array}{r}-1.34 \cdot 4 \\
(69 \cdot 2)\end{array}$ & & & $22 \cdot 3$ \\
\hline Birth weight $=$ & $\begin{array}{c}-4567 \\
(1066)\end{array}$ & $\begin{array}{r}+11 \cdot 70 \\
(4 \cdot 70)\end{array}$ & $\begin{array}{r}+153 \cdot 3 \\
(20 \cdot 8)\end{array}$ & $\begin{array}{r}+121 \cdot 6 \\
(57 \cdot 1)\end{array}$ & $\begin{array}{c}-128 \cdot 1 \\
(69 \cdot 4)\end{array}$ & $\begin{array}{c}-94 \cdot 1 \\
(67 \cdot 5)\end{array}$ & $\begin{array}{c}-30 \cdot 6 \\
(79 \cdot 0)\end{array}$ & $22 \cdot 9$ \\
\hline Birth weight $=$ & $\begin{array}{c}-4579 \\
(1062)\end{array}$ & $\begin{array}{r}+12 \cdot(01 \\
(4 \cdot 69)\end{array}$ & $\begin{array}{r}+150 \cdot 6 \\
(20 \cdot 6)\end{array}$ & $\begin{array}{r}+122.7 \\
(57 \cdot 1)\end{array}$ & $\begin{array}{r}-133 \cdot 5 \\
(69 \cdot 1)\end{array}$ & & & $22 \cdot 7$ \\
\hline
\end{tabular}

${ }^{*} r^{2}$ Represents extent to which equation explains variation in birth weight: $100 \%$ represents complete explanation.

The coefficients represent the birthweight increment (or decrement) in grams predicted from a unit increment in each 'explanatory' variable. For example, in the first equation, each additional centimetre of maternal height would be associated with a $12 \mathrm{~g}$ increase in birth weight. The sex 'variable' reflects the increment for a boy compared with a girl. The parity variable is the decrement for the first born child compared with subsequent children. Similarly, the 'first cousin' and 'distant' measurements show the decrement in birth weight if the parents are in one of these categories compared with being unrelated. 


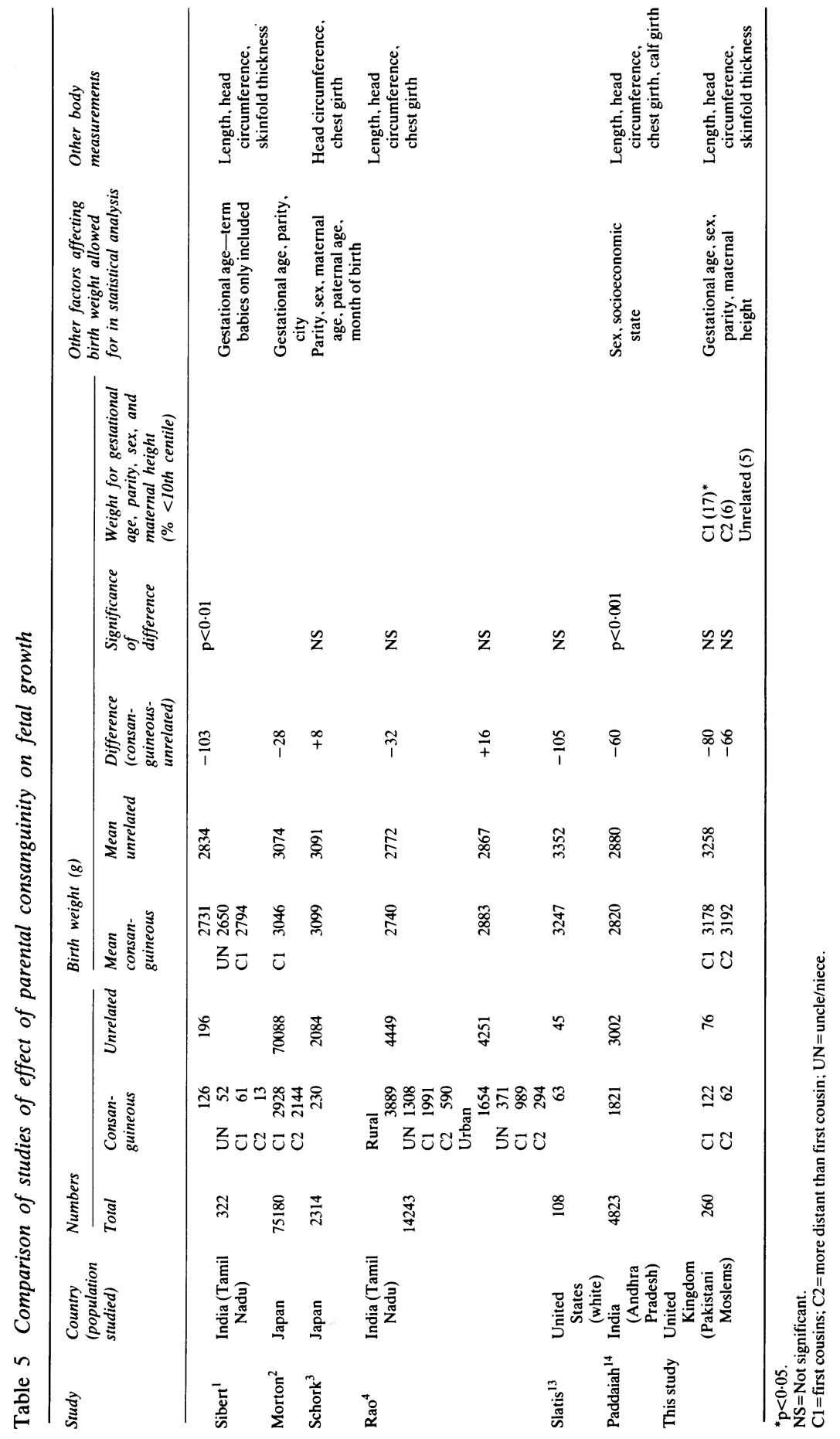




\section{Discussion}

Table 5 summarises the results of this and previous studies. ${ }^{1-4} 1314$ There is conflicting evidence for the effect of parental consanguinity on fetal growth, but in almost all studies the mean birth weight of the related groups was lower than that of the unrelated groups. In this study, although a reduction of $80 \mathrm{~g}$ was found in the first cousin group compared with the unrelated group, the difference was not significant for the size of the sample studied, which was chosen to detect a difference in birth weight of $100 \mathrm{~g}$ or more.

Two different statistical techniques found consanguinity to have no significant effect on birth weight after allowing for gestational age, sex, parity, and maternal height - that is, the overall distributions of birthweight centiles were no different and multiple regression found only a minimal effect. There were significantly more babies in the first cousin group, however, who were below the 10th centile for birth weight. Of these light babies in the first cousin group, half were also short (length below the 10th centile) and one quarter uniformly small (length and head circumference below the 10th centile). Proportionately fewer of the babies less than 10th centile in the other groups were uniformally small, but the total numbers were small and not significant.

If parental consanguinity does have a growth retarding effect it is therefore not clear whether it acts by depressing all growth variables from an early stage or whether weight gain is more affected at a later stage in pregnancy, possibly as a result of poorer placental function. Growth retardation may also be part of a recognised recessively inherited condition (Table 4 , case 1 ), but this mechanism is likely to have little overall effect on the mean birth weight. While the excess of babies with congenital abnormalities of varying severity in the related groups was striking, this prospective study was not designed to investigate this controversial question, ${ }^{4} 15$ and further studies are awaited.

Although the validity of using the adjustments of Thomson et al on an Asian population has not been established, the same criteria for adjustment was applied to all groups and indeed the centile distribution of our unrelated group was close to that of their reference population. Perhaps this 'significant finding' is a mere statistical artefact, reflecting the arbitrary nature of the 10th centile cut off point. Nevertheless, this cut off point is in wide clinical use to indicate babies who may require special attention in the newborn period.

We thank Mr H N Mansfield, Mr P G Needham, and Mr J R Pogmore for access to the mothers in their care, Mrs Nadeem for interpretation, the Medical Illustration Department, Birmingham Children's Hospital, for the Figure, and Mrs P Cox and Mrs S Kane for secretarial help. LB was a Commonwealth Scholar during this study.

\section{References}

1 Sibert JR, Jadhav M. Inbaraj SG. Fetal growth and parental consanguinity. Arch Dis Child 1979;54:317-9.

2 Morton NE. Empirical risks in consanguinous marriages: birth weight, gestational time and measurements of infants. Am J Hum Genet 1958:10:344-9.

${ }^{3}$ Schork MA. The effects of inbreeding on growth. Am J Hum Genet 1964:16:292-9.

4 Rao PSS, Inbaraj SG. Inbreeding effects on fetal growth and development. J Med Genet 1980:17:27-33.

5 Clarson CL. Barker MJ. Marshall T. Wharton BA. Secular change in birth weight of Asian babies born in Birmingham. Arch Dis Child 1982:57:867-71.

${ }^{6}$ Vicgas OAC. Scott PH, Cole TJ. Mansfield HN, Wharton P. Wharton BA. Dietary protein energy supplementation of pregnant Asian mothers at Sorrento. Birmingham. I: Unselective during second and third trimesters. $\mathrm{Br}$ Med J 1982:285: 589-92.

7 Vicgas OAC. Scott PH. Cole TJ, Eaton P. Needham PG. Wharton BA. Dietary protein energy supplementation of pregnant Asian mothers at Sorrento. Birmingham. II: Selective during third trimester only. Br Med J 1982:285:592-5.

* Armitage P. Statistical methods in medical research. Oxford: Blackwell Scientific Publications. 1971:184-8.

"Thomson AM. Billewicz WZ. Hytten FE. The assessment of fctal growth. Journal of Obstetrics and Gynaecology of the British Commonwealth 1968:75:903-16.

11) Altman DG. Coles EC. Nomograms for precise determination of birth weight for dates. Br J Obstet Gynaecol 1980;87:81-6.

" Gairdner D. Pearson J. A growth chart for premature and other infants. Arch Dis Child 1971:46:783-7.

12 Armitage P. Statistical methods in medical research. Oxford: Blackwell Scientific Publications, 1971:331-2.

1.3 Slatis HM. Hoene RE. The effect of consanguinity on the distribution of continuously variable characteristics. Am J Hum Genet 1961:13:28-31.

${ }^{14}$ Paddaiah G. Reddy GG. Effect of consanguinity on anthropometric measurements in the newborn. Ind $J$ Pediatr 1980:47:133-6.

15 Schull WJ. Empirical risks in consanguineous marriages: sex ratio malformation, and viability. Am J Hum Genet 1958:10:294-343.

Correspondence to Dr B A Wharton, Maternal and Child Health Unit, Sorrento Maternity Hospital, Wake Green Road, Moscley, Birmingham B13 9HE. England.

Received 20 October 1986 